\title{
In-cloud measurements highlight the role of aerosol hygroscopicity in cloud droplet formation
}

\author{
Olli Väisänen ${ }^{1}$, Antti Ruuskanen ${ }^{2}$, Arttu Ylisirniö ${ }^{1}$, Pasi Miettinen ${ }^{1}$, Harri Portin ${ }^{3}$, Liqing Hao ${ }^{1}$, Ari Leskinen ${ }^{1,2}$, \\ Mika Komppula $^{2}$, Sami Romakkaniemi ${ }^{2}$, Kari E. J. Lehtinen ${ }^{1,2}$, and Annele Virtanen \\ ${ }^{1}$ University of Eastern Finland, Department of Applied Physics, P.O. Box 1627, 70211 Kuopio, Finland \\ ${ }^{2}$ Finnish Meteorological Institute, P.O. Box 1627, 70211 Kuopio, Finland \\ ${ }^{3}$ Helsinki Region Environmental Services Authority, P.O. Box 100, 00066 HSY, Finland
}

Correspondence to: Annele Virtanen (annele.virtanen@uef.fi)

Received: 15 April 2016 - Published in Atmos. Chem. Phys. Discuss.: 21 April 2016

Revised: 13 July 2016 - Accepted: 3 August 2016 - Published: 17 August 2016

\begin{abstract}
The relationship between aerosol hygroscopicity and cloud droplet activation was studied at the Puijo measurement station in Kuopio, Finland, during the autumn 2014. The hygroscopic growth of 80,120 and $150 \mathrm{~nm}$ particles was measured at $90 \%$ relative humidity with a hygroscopic tandem differential mobility analyzer. Typically, the growth factor (GF) distributions appeared bimodal with clearly distinguishable peaks around 1.0-1.1 and 1.4-1.6. However, the relative contribution of the two modes appeared highly variable reflecting the probable presence of fresh anthropogenic particle emissions. The hygroscopicitydependent activation properties were estimated in a case study comprising four separate cloud events with varying characteristics. At 120 and $150 \mathrm{~nm}$, the activation efficiencies within the low- and high-GF modes varied between 0 34 and $57-83 \%$, respectively, indicating that the less hygroscopic particles remained mostly non-activated, whereas the more hygroscopic mode was predominantly scavenged into cloud droplets. By modifying the measured GF distributions, it was estimated how the cloud droplet concentrations would change if all the particles belonged to the more hygroscopic group. According to $\kappa$-Köhler simulations, the cloud droplet concentrations increased up to $70 \%$ when the possible feedback effects on effective peak supersaturation (between 0.16 and $0.29 \%$ ) were assumed negligible. This is an indirect but clear illustration of the sensitivity of cloud formation to aerosol chemical composition.
\end{abstract}

\section{Introduction}

Atmospheric aerosols play a key role in the global climate system. They can affect the Earth's radiation balance either directly by scattering and absorbing the solar radiation, or indirectly, via clouds. Despite their relatively long-known influence pathways, atmospheric aerosols and especially their interactions with clouds, are still recognized as the most important source of uncertainty in the estimates of radiative forcing over the industrial period (IPCC, 2013). Although the climatic sensitivity and clouds are linked via numerous feedback mechanisms, one fundamental key towards a diminished uncertainty is to understand the factors controlling the particle's ability to act as cloud condensation nuclei (CCN).

The particles' ability to activate into cloud droplets at a certain level of supersaturation depends on their size and chemical composition. The role of particle size is already quite well identified and it is commonly considered as the most important factor. For example, according to the early model calculations by Junge and McLaren (1971) and measurements by Fitzgerald (1973), the shape of the CCN spectrum was predominantly determined by the initial particle size distribution, and compositional variations became significant only when the aerosol was highly insoluble. More recently, Dusek et al. (2006) estimated that the changes in aerosol size distribution explained over $80 \%$ of the observed variance in CCN concentration. Similarly, Ervens et al. (2007) stated that the CCN predictions were the most sensitive to variations in particle size distribution and supersaturation. 
Considering the great climatological uncertainty related to aerosol-cloud interactions, such a straightforward relationship between aerosol size distributions and CCN spectra could substantially improve the estimates of the aerosol indirect radiative forcing. However, as Hudson (2007) stated, the estimation by Dusek et al. (2006) was based on a rather small variation in chemical composition, which may have led to considerable underestimation of its role in cloud droplet activation. In addition, Quinn et al. (2008) parametrized the aerosol chemical composition by using the mass fraction of hydrocarbon-like organic aerosol (HOA) and combined the results with $\mathrm{CCN}$ activity measurements. The results indicated that the uncertainty between the measured and estimated CCN concentrations was up to $50 \%$ when the variations in HOA were neglected.

During the last few decades, a lot of effort has been put into $\mathrm{CCN}$ closure studies, i.e., determination of $\mathrm{CCN}$ concentration by means of size and composition related properties (Broekhuizen et al., 2006; Conant et al., 2004; Ervens et al., 2007; Fountoukis et al., 2007). CCN closure studies allow to assess the importance of different parameters on cloud droplet activation and therefore they are an important tool towards a sufficient understanding of the link between atmospheric aerosols and cloud processes. One specific method includes the determination of CCN spectra by means of hygroscopicity measurements. Under subsaturated conditions (i.e., relative humidity $(\mathrm{RH})<100 \%$ ), aerosol hygroscopicity can be characterized by using a parameter called hygroscopic growth factor

$\mathrm{GF}\left(\mathrm{RH}, D_{\mathrm{p}}\right)=\frac{D_{\text {wet }}\left(\mathrm{RH}, D_{\mathrm{p}}\right)}{D_{\mathrm{p}}}$,

where $D_{\text {wet }}$ is the wet particle diameter at a certain $\mathrm{RH}$ and $D_{\mathrm{p}}$ is the corresponding dry diameter. In principle, GFs reflect the aerosol chemical composition. Pure inorganic salts such as sodium chloride $(\mathrm{NaCl})$ and ammonium sulfate $\left(\left(\mathrm{NH}_{4}\right)_{2} \mathrm{SO}_{4}\right)$ are usually associated with elevated growth factors $(\mathrm{GF}>1.60$ at $\mathrm{RH}=90 \%)$, whereas some other species appear clearly less hygroscopic (McFiggans et al., 2006). For example, fresh mineral dust and pure black carbon are almost hydrophobic with typical GFs below 1.05 (Vlasenko et al., 2005; Weingartner et al., 1997; Liu et al., 2013). In atmospheric conditions, the average GFs usually vary between 1.0 and 1.8, and the GF distributions may consist of several independent modes originating from various sources of particulate matter (Ferron et al., 2005; Fors et al., 2011; Sjogren et al., 2008; Liu et al., 2011; McFiggans et al., 2006).

In order to better understand the relationship between cloud droplet activation, aerosol chemical composition and hygroscopicity, we organized an intensive measurement campaign at the Puijo measurement station in Kuopio, Eastern Finland, during the autumn 2014 (Puijo Cloud Experiment 2014). Along with the Global Atmospheric Watch (GAW) stations such as Pallas, Finland (Komppula et al.,
2005), Jungfraujoch, Switzerland (Sjogren et al., 2008) and Puy-de-Dôme, France (Asmi et al., 2012), the Puijo station is one of the few measurement sites where long-term continuous in situ measurements on aerosol-cloud interactions are being carried out. Therefore, it provides an established base for detailed aerosol and cloud studies. Utilizing the conducted in-cloud measurements, this paper aims to identify the hygroscopicity-dependent activation properties of a cloudforming aerosol population and study the effects of varying chemical composition on cloud droplet formation.

\section{Methods}

\subsection{Measurement site}

The measurement campaign took place at the Puijo SMEAR IV station in Kuopio, Finland (around $340 \mathrm{~km}$ to NE from Helsinki) between 17 September and 4 November 2014. The measurement station is located at the top of the Puijo observation tower $\left(62^{\circ} 54^{\prime} 34^{\prime \prime} \mathrm{N}, 27^{\circ} 39^{\prime} 19^{\prime \prime} \mathrm{E}\right)$ approximately $224 \mathrm{~m}$ above the surrounding lake level (Leskinen et al., 2009; Ahmad et al., 2013; Portin et al., 2014). The station was established in 2005 and since then it has provided continuous data on aerosol and cloud droplet size distributions, aerosol optical properties, atmospheric trace constituents and various weather parameters. Due to the diverse surroundings, the measurement site can be characterized as a semi-urban environment. The eastern side of the tower $\left(0-215^{\circ}\right)$ includes several local pollution sources such as a paper mill in the northeast, the city center in the southeast, a heating plant in the south and the two main roads in south-north direction, as well as residential areas with occasional domestic biomass combustion. By contrast, the western sector $\left(215-360^{\circ}\right)$ has no important local sources besides the relatively small residential areas. For more detailed overview of the station and local pollution sources, see Leskinen et al. (2012) and Portin et al. (2014).

\subsection{Weather data and cloud events}

Temperature, visibility, wind speed, wind direction, precipitation, air pressure and relative humidity were measured continuously during the campaign. Visibility and precipitation were measured with a Vaisala FD12P weather sensor, wind speed and direction with an ultrasonic two-dimensional anemometer (Thies UA2D), and temperature and relative humidity with a Vaisala HMT337 temperature and humidity transmitter. Based on meteorological conditions, the measurement period was divided into cloudy and cloud-free sub-periods. Cloud events were defined as continuous periods (duration more than $1 \mathrm{~h}$ ) with visibility below $200 \mathrm{~m}$. For cloud-free conditions, the lower visibility limit was set to $8000 \mathrm{~m}$ in order to avoid the biasing effects of nonuniform clouds and fog. In addition, the observed events were classified as rainy if the average rain intensity exceeded 
$0.2 \mathrm{~mm} \mathrm{~h}^{-1}$. However, these cases were omitted from the analyses, since precipitation removes both activated and nonactivated particles from the atmosphere causing a possible source of error for the measurement data.

\subsection{Twin inlet system and size distribution measurements}

During the campaign, we utilized a custom made twin inlet system (Portin et al., 2014) consisting of two separate sample lines in order to measure total and non-activated (interstitial) particles separately. The total air inlet had an approximate cut-off diameter of $40 \mu \mathrm{m}$ and the sample line was heated to $30-40^{\circ} \mathrm{C}$. Due to the heating, liquid water was evaporated from the droplets and residual particles were formed. Thus, when the top of the tower was inside a cloud, the total flow contained both the residual and interstitial particles. Meanwhile, the interstitial sample line was equipped with a $\mathrm{PM}_{1.0}$ impactor (lower cut-off limit of $1 \mu \mathrm{m}$ ) to prevent the cloud droplets from entering the sampling system. During cloudfree conditions, both of the inlets sampled the same aerosol population.

Aerosol size distributions from 3 to $800 \mathrm{~nm}$ were measured with a twin differential mobility particle sizer (twin-DMPS). In this setup, two independent DMPSs measured the particle diameters from 3 to $53 \mathrm{~nm}$ and from 30 up to $800 \mathrm{~nm}$ with aerosol/sheath flow ratios of $1.4: 23$ and $1: 5.5$, respectively. The instruments were attached to the twin inlet system with an automated valve, which was operated to switch between the sampling lines in $6 \mathrm{~min}$ intervals. Consequently, the total measurement time for total and interstitial population was $12 \mathrm{~min}$, assuming that the aerosol was not changing during the cycle. Full data inversion was applied to the raw data including corrections for sampling losses, multiple charging probabilities, instrumental transfer functions and particle counting efficiencies as recommended by Wiedensohler et al. (2012).

\subsection{HTDMA experiments}

Aerosol hygroscopicity under subsaturated conditions was measured with a hygroscopic tandem differential mobility analyzer (HTDMA, Table S1 in the Supplement). Briefly, HTDMA consists of two differential mobility analyzers (DMA) and a humidifier. The first DMA (DMA1) selects the dry size of interest and the second DMA (DMA2) coupled with a condensation particle counter (CPC) measures the resulting size distribution, after the nearly monodisperse aerosol sample has been exposed to certain RH. During the campaign, the initial dry sizes were 80,120 and $150 \mathrm{~nm}$ and the $\mathrm{RH}$ inside the DMA2 ( $\left.\mathrm{RH}_{\mathrm{DMA} 2}\right)$ was adjusted to $\sim 90 \%$. Both of the DMAs were $28 \mathrm{~cm}$ long Vienna type DMAs (Winklmayr et al., 1991) operated with flow ratios of $1: 6$, and the RH control of the sheath air inside DMA2 was achieved by using a closed-loop circulation. The resi- dence time inside the aerosol humidifier was approximately $0.2 \mathrm{~s}$, after which the particles spent $\sim 2 \mathrm{~s}$ in elevated RH before entering the DMA2. The propagated instrumental uncertainty associated with the measured GFs was approximately $\pm 4.5 \%$.

The HTDMA was attached to the twin inlet system for a 4-week period (26 September-20 October; hereafter referred to as a twin inlet period) in the middle of the campaign. Otherwise, total aerosol was being measured continuously. During the twin inlet period, an external valve system switched between the two sampling lines in $24 \mathrm{~min}$ intervals. Therefore, the duration of individual size scans was adjusted so that the whole measurement cycle with three initial dry sizes was performed twice between each line change. However, some of the data points had to be removed afterwards because the line change had occurred during an ongoing size scan. In the case of continuous total line measurements, each size scan took 5 min.

The average hygroscopic growth factors and their probability density functions (GF-PDF) were evaluated using the TDMAinv inversion toolkit (Gysel et al., 2009). The procedure calculates the broadening factor of the instrumental transfer function from dry size measurements and then describes the inverted GF-PDFs as piecewise linear functions. For this purpose, dry size scans with ammonium sulfate particles were performed at low RH before and during the campaign. The inversion algorithm was operated to solve the GF-PDFs with a resolution of $\Delta \mathrm{GF}=0.10$ and only the size scans with average $\mathrm{RH}_{\mathrm{DMA} 2}$ between 88 and $92 \%$ were taken into account in the analysis. In addition these data points were corrected to the $90 \%$ target RH by using the built-in $\gamma$-model within the inversion toolkit. Briefly, $\gamma$ correction adjusts the measured growth factors to the desired $\mathrm{RH}$ by applying a parametrization $\mathrm{GF}=(1-\mathrm{RH})^{-\gamma}$, where $\gamma$ is first calculated from the original measurement data and then substituted backwards to obtain the RH corrected GF.

\subsection{Derivation of $N_{\text {act, HTDMA }}$}

According to the Köhler theory (Köhler, 1936), the equilibrium saturation ratio, $S_{\mathrm{eq}}$, over a liquid droplet can be calculated by

$S_{\text {eq }}=a_{\mathrm{w}} \exp \left(\frac{4 M_{\mathrm{w}} \sigma}{R T \rho_{\mathrm{w}} D_{\text {wet }}}\right)$,

where $a_{\mathrm{W}}$ is the water activity, $M_{\mathrm{w}}$ the molar weight of water, $\sigma$ the surface tension (here, assumed to be that of water, $0.072 \mathrm{~J} \mathrm{~m}^{-2}$ ), $R$ the universal gas constant, $T$ the ambient temperature and $\rho_{\mathrm{w}}$ the density of water. In order to relate the measured growth factors to water activities, we used the $\kappa$ Köhler model described by Petters and Kreidenweis (2007). With $\kappa$-Köhler model, the water activity can be parametrized as

$\frac{1}{a_{\mathrm{w}}}=1+\kappa \frac{V_{\mathrm{p}}}{V_{\mathrm{w}}}$, 
where $V_{\mathrm{p}}$ and $V_{\mathrm{w}}$ are the dry particle and water volumes, and $\kappa$ is the hygroscopicity parameter determined as below:

$\kappa\left(\mathrm{GF}, D_{\mathrm{p}}, \mathrm{RH}\right)=\frac{\left(\mathrm{GF}^{3}-1\right) \exp \left(\frac{4 M_{\mathrm{w}} \sigma}{R T \rho_{\mathrm{w}} D_{\mathrm{p}} \mathrm{GF}}\right)}{\mathrm{RH}}-\mathrm{GF}^{3}+1$.

Alternatively, the relationship between $\kappa$ and critical saturation ratio, $S_{\mathrm{c}}$, i.e., the maximum of the Köhler curve (Eq. 2), can be approximated by

$\kappa\left(D_{\mathrm{p}}, S_{\mathrm{c}}\right)=\frac{4 A^{3}}{27 D_{\mathrm{p}}^{3} \ln ^{2} S_{\mathrm{c}}}$,

where $A=4 M_{\mathrm{w}} \sigma / R T \rho_{\mathrm{w}}$. Thus, by combining the Eqs. (4) and (5) and by assuming a certain value for $S_{\mathrm{c}}$, it is possible to estimate the critical growth factor, $\mathrm{GF}_{c}$, i.e., the required growth factor for particles with dry size $D_{\mathrm{p}}$ to become activated at the given supersaturation. Thereafter, the sizeresolved activation efficiency $f_{\text {act,HTDMA }}$ can be calculated according to

$$
f_{\text {act,HTDMA }}\left(D_{\mathrm{p}}, S_{\mathrm{c}}\right)=\int_{\mathrm{GF}_{\mathrm{c}}\left(D_{\mathrm{p}}, S_{\mathrm{c}}\right)}^{\infty} \mathrm{GF}-\operatorname{PDF}\left(\mathrm{GF}, D_{\mathrm{p}}\right) d \mathrm{GF} .
$$

Furthermore, the available CCN concentration can be obtained by weighting the measured particle size distribution with the activation efficiency and by integrating over the whole size range:

$N_{\text {act,HTDMA }}\left(S_{\mathrm{c}}\right)=\int_{-\infty}^{\infty} f_{\text {act,HTDMA }}\left(D_{\mathrm{p}}, S_{\mathrm{c}}\right) \frac{d N_{\text {tot }}}{d \log D_{\mathrm{p}}} d \log D_{\mathrm{p}}$.

In order to solve the preceding equation, the GF-PDFs determined for $D_{\mathrm{p}}=80,120$ and $150 \mathrm{~nm}$ were linearly interpolated to cover the whole size range of interest. This was done by interpolating the GF-PDFs over the measurement range $(80-150 \mathrm{~nm})$ and then extrapolating up to $200 \mathrm{~nm}$. In addition, the 80 and $200 \mathrm{~nm}$ GF-PDFs were assumed to be representative for particles smaller than $80 \mathrm{~nm}$ and larger than $200 \mathrm{~nm}$, respectively.

The procedure follows the principles described previously by, e.g., Kammermann et al. (2010b) and Fors et al. (2011), except that here we did not have an independent HTDMA data point around $200-250 \mathrm{~nm}$. Therefore, extrapolation towards larger sizes is also the main source of uncertainty, as underestimation of aerosol hygroscopicity could possibly lead to underestimation of $f_{\text {act,HTDMA }}$ and vice versa. Secondly, the method assumes that the subsaturated hygroscopicities are representative for supersaturated conditions. Such an assumption is not always totally valid and discrepancies between the two saturation regimes have been reported based on laboratory and field experiments (Good et al., 2010; Hersey et al., 2013; Jaatinen et al., 2014; Pajunoja et al., 2015). Typically, the subsaturated hygroscopicities can appear somewhat lower than the supersaturated ones, which may result in underestimation of $\mathrm{CCN}$ concentration at a fixed supersaturation. On the other hand, for example Jurányi et al. (2013) found a very good closure between the sub- and supersaturated regimes for an externally mixed urban aerosol in Paris, France.

In order to estimate the cloud droplet concentration in atmospherically relevant conditions, the effective peak supersaturation, $s_{\mathrm{c} \text {,eff }}$ (where $s_{\mathrm{c}, \text { eff }}=S_{\mathrm{c} \text {,eff }}-1$ ), was approximated by minimizing the difference between the measured and estimated activation curves, i.e., by minimizing the norm

$\left\|R\left(S_{\mathrm{c}}\right)\right\|=\sqrt{\sum_{\mathrm{i}}\left[f_{\text {act, HTDMA }}\left(D_{\mathrm{p}, \mathrm{i}}, S_{\mathrm{c}}\right)-f_{\mathrm{act}, \mathrm{DMPS}}\left(D_{\mathrm{p}, \mathrm{i}}\right)\right]^{2}}$,

where $D_{\mathrm{p}, \mathrm{i}}$ was limited to vary from 80 to $200 \mathrm{~nm}$, and the DMPS derived activation efficiency, $f_{\text {act,DMPS }}$, was determined by means of total and interstitial particle size distributions as follows:

$f_{\text {act,DMPS }}\left(D_{\mathrm{p}}\right)=\frac{\frac{d N_{\text {tot }}}{d \log D_{\mathrm{p}}}\left(D_{\mathrm{p}}\right)-\frac{d N_{\text {int }}}{d \log D_{\mathrm{p}}}\left(D_{\mathrm{p}}\right)}{\frac{d N_{\text {tot }}}{d \log D_{\mathrm{p}}}\left(D_{\mathrm{p}}\right)}$.

In principle, the effective peak supersaturation can be described as the maximum supersaturation that the particles experience for an adequate time to form stable cloud droplets (Hammer et al., 2014). It is also important to point out that this kind of approach masks the potential discrepancies between the two saturation regimes, and underestimation of supersaturated hygroscopicity would eventually lead to positive bias in $s_{\mathrm{c}, \text { eff }}$.

In addition to the "externally mixed approach" described above, the cloud droplet concentrations were estimated under an assumption that the ambient aerosol was completely internally mixed. In this approach, the interpolated GF surfaces were used to calculate the average hygroscopicity parameter $\kappa_{\text {avg }}$ (Eq. 4) for each dry size. These values were then compared to critical $\kappa$ values approximated by using the Eq. (5) and the previously determined $S_{\mathrm{c} \text {,eff. }}$. Furthermore, depending on whether the $\kappa_{\text {avg }}$ was higher or lower than the respective critical value, the activation efficiency was assumed to be either 1 or 0 , respectively. Therefore, this kind of internally mixed approach resulted in activation efficiency curves resembling a step function instead of S-shaped curves obtained by means of full GF-PDFs.

\section{Results and discussion}

\subsection{Weather parameters and cloud events}

During the campaign, the hourly averaged ambient temperatures varied between -9.7 and $15.3{ }^{\circ} \mathrm{C}$, with sub-zero temperatures occurring mostly during the latter half of the measurement period. Due to the diurnal temperature variations, relative humidity usually reached its daily maxima during the nighttime and early morning hours. Therefore, most of the 

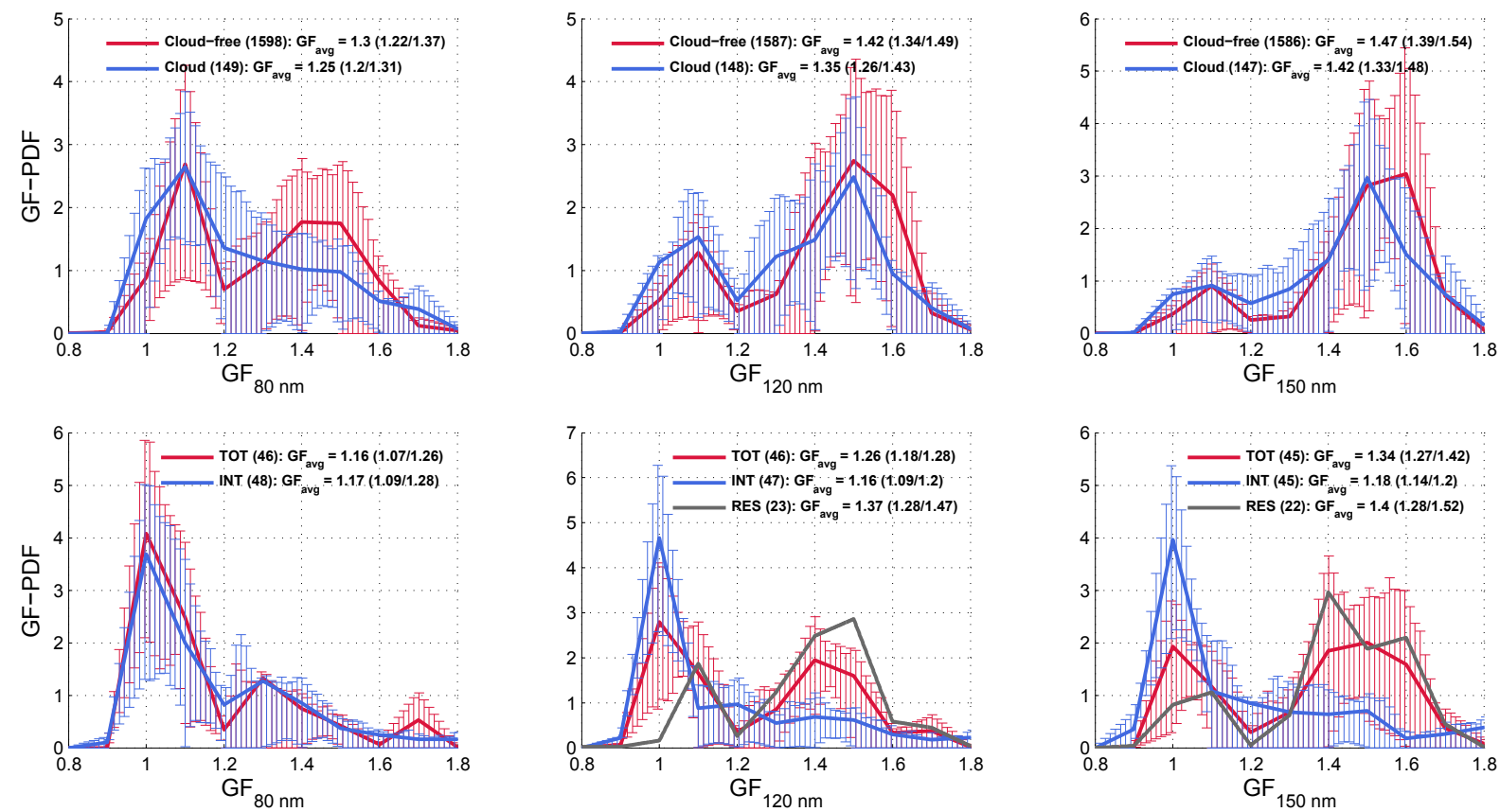

Figure 1. Top row: average hygroscopicity of total aerosol at $90 \% \mathrm{RH}$ during cloudy (blue) and cloud-free (red) conditions (whole campaign). Bottom row: average in-cloud hygroscopicity of total (red), interstitial (blue) and residual aerosol (black) during the twin inlet period. The values shown in the parentheses represent the number of averaged observations and the 25 th and 75 th percentiles. In the graphs, the lower and upper quartiles are illustrated with whiskers.

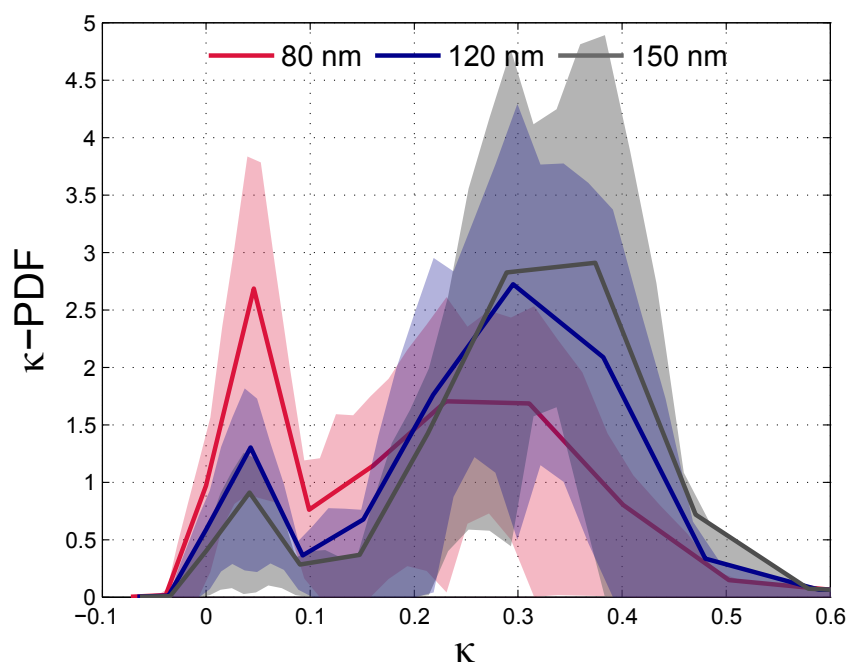

Figure 2. Mean $\kappa$-PDFs of 80,120 and $150 \mathrm{~nm}$ particles calculated over the whole data set. The shaded areas represent the ranges between the 25th and 75 th percentiles.

cloud formation events also occurred within these time periods. Generally, the wind speeds exhibited a diurnal variation similar to ambient RH with slightly increased velocities during the nighttime. The wind was blowing from southwestern directions $\left(180-270^{\circ}\right)$ approximately $39 \%$ of time, and during cloud events this fraction was even higher, roughly $50 \%$.
Altogether, the tower was inside a cloud approximately $10 \%$ of time, which is somewhat less compared to typical autumn conditions at Puijo (Portin et al., 2009). In total, 15 nonprecipitating cloud events were observed during the campaign, providing up to 47 cloud event hours.

\subsection{Hygroscopicity at Puijo}

Figure 1 shows the average GFs and GF-PDFs observed at Puijo during the campaign period. Overall, the measured GFs varied between $\sim 1$ and $\sim 1.7$ reaching the campaign averages ( \pm 1 standard deviation) of $1.30 \pm 0.11(80 \mathrm{~nm})$, $1.42 \pm 0.10(120 \mathrm{~nm})$ and $1.47 \pm 0.10(150 \mathrm{~nm})$. A closer look at the GF-PDFs indicates that there are two main factors affecting the observed size dependence. In general, the GF-PDFs appear bimodal with clearly distinguishable peaks around 1.0-1.1 and 1.4-1.6. However, the number fraction of less hygroscopic particles $\left(f_{\mathrm{GF}}<1.25\right)$ decreases with increasing particle size, and at the same time, the more hygroscopic mode tends to shift slightly towards larger growth factors. A similar shift is also apparent in Fig. 2 where the average hygroscopicity distributions are plotted as $\kappa$-PDFs. Furthermore, this indicates that the transition towards higher GFs can be attributed both to Kelvin effect as well as changes in chemical composition.

According to a wind sector analysis (see supplementary material for further details), the polluted sector was characterized by higher $f_{\mathrm{GF}}<1.25$ than the clean one, but on the other 
hand, the more hygroscopic mode shifted towards higher GFs suppressing the differences in average GFs. Tiitta et al. (2010) studied the particulate roadside emissions in Kuopio and observed an elevated non-hygroscopic particle mode $\left(D_{\mathrm{p}} \leq 50 \mathrm{~nm}\right)$ originating from fresh exhaust emissions. A similar observation was also made by Laborde et al. (2013) in Paris with particle sizes up to $265 \mathrm{~nm}$. Against this background, it is probable that the less hygroscopic fraction observed at Puijo is also linked to the traffic and other anthropogenic sources of organic aerosol.

Minor differences can be seen also in the GF-PDFs between cloudy and cloud-free conditions (Fig. 1). The fraction of more hygroscopic particles is slightly enhanced during cloud-free conditions, resulting in higher average GFs. This can be due to the limited timescale of cloud events and varying contribution of local pollution, together with possibility for in-cloud processing and precipitation scavenging. However, for example Henning et al. (2014) and Zelenyuk et al. (2010) reported a cloud-induced sulfate enrichment in the particle phase, which should eventually result in increasing hygroscopicity. One may also note that the in-cloud distributions measured during the twin inlet period differ considerably from the campaign averages with substantially stronger contribution of $f_{\mathrm{GF}<1.25}$ at $D_{\mathrm{p}}=120$ and $150 \mathrm{~nm}$. Again, the most probable explanation is the enhanced presence of local pollution due to more frequent easterly winds.

As indicated above, the analytical division between the less and more hygroscopic particles was done by using a GF limit of 1.25 . The value represents a common midpoint between the two GF modes and it has been used in several preceding studies (e.g., Kammermann et al., 2010a; Jurányi et al., 2013; Portin et al., 2014). Averaged over the whole campaign, the size-dependent less hygroscopic fractions were $0.44 \pm 0.25(80 \mathrm{~nm}), 0.22 \pm 0.17(120 \mathrm{~nm})$ and $0.15 \pm 0.14$ $(150 \mathrm{~nm})$. Together with the average GF-PDFs, these values are comparable to hygroscopicities observed at a background site in southern Sweden (Fors et al., 2011). However, as seen during the twin inlet period, our site experienced reasonably strong variation in less hygroscopic fraction with $f_{\mathrm{GF}}<1.25$ regularly reaching the levels of urban conditions (McFiggans et al., 2006). For example during the observed cloud hours, the average $f_{\mathrm{GF}}<1.25$ ranged from 0 up to 0.62 at $D_{\mathrm{p}}=150 \mathrm{~nm}$. By comparison, Jurányi et al. (2013) studied the aerosol mixing state in Paris, France and reported typical values varying between $\sim 0.20$ and $\sim 0.60$ at $D_{\mathrm{p}}=165 \mathrm{~nm}$. In addition, Ferron et al. (2005) observed that in urban and semi-urban conditions, the non-hygroscopic mode could be dominant at particle sizes up to $250 \mathrm{~nm}$, especially during the autumn and winter seasons.

\subsection{Hygroscopic properties of total, interstitial and residual aerosol}

The GF-dependent activation efficiencies $\left(f_{\text {act, GF }}\right)$ were derived from the measured GF-PDFs according to

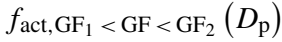

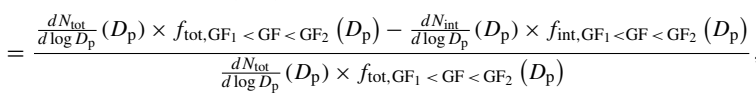

where $f_{\text {tot, } \mathrm{GF} 1<\mathrm{GF}<\mathrm{GF} 2}$ and $f_{\text {int, }} \mathrm{GF} 1<\mathrm{GF}<\mathrm{GF} 2$ were the total and interstitial number fractions of particles with dry size $D_{\mathrm{p}}$ and $\mathrm{GF}$ between $\mathrm{GF}_{1}$ and $\mathrm{GF}_{2}$. The average activation efficiencies were calculated separately for each cloud event and for three different GF regimes (GF $\geq 0.80,0.80 \leq \mathrm{GF}<1.25$ and $\mathrm{GF} \geq 1.25$ ). Here it should be noted that the activation efficiencies can appear negative if the averaged interstitial concentrations are higher than the corresponding total values. This can be the case especially within the less hygroscopic regime where the activated fractions are generally low. In such cases, the negative activation efficiencies are reported as zeros and treated as such when calculating the total activated fractions $\left(f_{\text {act, } G F} \geq 0.80\right)$. Thus, the resulting $f_{\text {act, } G F} \geq 0.80$ values can be slightly different from those derived solely from DMPS measurements.

A total of nine cloud events were observed during the twin inlet period. Due to the reasonably low time resolution of HTDMA size scans and slow alteration between the two sampling lines, data with good coverage and reasonable agreement between $f_{\text {act, GF }} \geq 0.80$ and $f_{\text {act,DMPS }}$ were available for four separate cloud events. These cases are summarized in Table 1. Because of the low activation efficiency of ultrafine particles, the activation parameters are presented only for 120 and $150 \mathrm{~nm}$ sizes.

The duration of the selected cloud events varied from $1 \mathrm{~h}$ 31 min (event \#2) to 4 h 25 min (event \#4). Cloud event \#1 had the highest particle and cloud droplet number concentrations, up to $2935 \mathrm{~cm}^{-3}$ and $781 \mathrm{~cm}^{-3}$, respectively, whereas much lower values were observed during the latter events. For example during the cloud event \#4, the particle and cloud droplet concentrations were down to 792 and $69 \mathrm{~cm}^{-3}$, respectively. These four cloud events were also characterized by very different wind patterns. Event \#2 was influenced by westerly winds blowing across the clean sector. By contrast, the wind was from the northeast during cloud event \#3 and from the southeast during the cloud event \#4. Furthermore, event \#1 was dominated by southwesterly winds blowing across the transition region between the clean and polluted sectors.

The most interesting remark, however, concerns the different activated fractions within the two GF modes. At $D_{\mathrm{p}}=120 \mathrm{~nm}$, the activation efficiencies of less hygroscopic particles varied from $0 \%$ to $4 \%$, whereas the values for more hygroscopic particles were much higher (between 57 and $70 \%$ ). A similar trend was observed also at $D_{\mathrm{p}}=150 \mathrm{~nm}$, 
Table 1. Overview of the four cloud events observed during the measurement campaign. Given are the total particle and cloud droplet number concentrations as well as the hygroscopicity-dependent activation efficiencies and growth factors of 120 and $150 \mathrm{~nm}$ particles. The number fraction of less hygroscopic particles is denoted by $f_{\mathrm{GF}}<1.25$.

\begin{tabular}{|c|c|c|c|c|c|c|c|c|}
\hline & \multicolumn{2}{|c|}{ Event \#1 } & \multicolumn{2}{|c|}{ Event \#2 } & \multicolumn{2}{|c|}{ Event \#3 } & \multicolumn{2}{|c|}{ Event \#4 } \\
\hline \multirow{4}{*}{$\begin{array}{l}\text { Time } \\
N_{\text {tot }} \\
N_{\text {act }}\end{array}$} & \multirow{3}{*}{\multicolumn{2}{|c|}{$\begin{array}{c}08 / 10,20: 46-23: 45 \\
2935 \mathrm{~cm}^{-3} \\
781 \mathrm{~cm}^{-3}\end{array}$}} & \multirow{3}{*}{\multicolumn{2}{|c|}{$\begin{array}{c}11 / 10,20: 25-21: 56 \\
699 \mathrm{~cm}^{-3} \\
135 \mathrm{~cm}^{-3}\end{array}$}} & \multirow{3}{*}{\multicolumn{2}{|c|}{$\begin{array}{c}13 / 10,05: 57-07: 40 \\
1442 \mathrm{~cm}^{-3} \\
158 \mathrm{~cm}^{-3}\end{array}$}} & \multirow{3}{*}{\multicolumn{2}{|c|}{$\begin{array}{c}20 / 10,00: 01-04: 26 \\
792 \mathrm{~cm}^{-3} \\
69 \mathrm{~cm}^{-3}\end{array}$}} \\
\hline & & & & & & & & \\
\hline & & & & & & & & \\
\hline & $120 \mathrm{~nm}$ & $150 \mathrm{~nm}$ & $120 \mathrm{~nm}$ & $150 \mathrm{~nm}$ & $120 \mathrm{~nm}$ & $150 \mathrm{~nm}$ & $120 \mathrm{~nm}$ & $150 \mathrm{~nm}$ \\
\hline$f_{\text {act,DMPS }}$ & 0.20 & 0.40 & 0.29 & 0.55 & 0.37 & 0.68 & 0.39 & 0.68 \\
\hline$f_{\text {act, }, \mathrm{GF}} \geq 0.80$ & 0.32 & 0.48 & 0.29 & 0.55 & 0.52 & 0.72 & 0.39 & 0.68 \\
\hline$f_{\text {act }, \mathrm{GF}<1.25}$ & 0 & 0 & 0 & 0.31 & 0 & 0 & 0.04 & 0.34 \\
\hline$f_{\mathrm{act}, \mathrm{GF}} \geq 1.25$ & 0.57 & 0.80 & 0.69 & 0.77 & 0.60 & 0.79 & 0.70 & 0.83 \\
\hline $\mathrm{GF}_{\mathrm{avg}, \mathrm{GF}} \geq 0.80$ & 1.27 & 1.31 & 1.20 & 1.25 & 1.58 & 1.65 & 1.27 & 1.41 \\
\hline $\mathrm{GF}_{\mathrm{avg}, \mathrm{GF}}<1.25$ & 1.13 & 1.13 & 1.05 & 1.06 & 1.00 & 1.00 & 1.01 & 1.02 \\
\hline $\mathrm{GF}_{\mathrm{avg}, \mathrm{GF}} \geq 1.25$ & 1.38 & 1.42 & 1.41 & 1.42 & 1.68 & 1.71 & 1.50 & 1.58 \\
\hline$f_{\mathrm{GF}}<1.25$ & 0.44 & 0.39 & 0.58 & 0.47 & 0.14 & 0.08 & 0.48 & 0.31 \\
\hline
\end{tabular}

with corresponding intervals of $0-34$ and $78-83 \%$, respectively.

One may also note that the hygroscopicity-dependent activation efficiencies increased with particle size. In the case of more hygroscopic particles, this was most likely attributed to Kelvin effect and small increments in respective hygroscopicities. Besides, the cloud events \#2 and \#4 were characterized by somewhat increased $f_{\text {act, } \mathrm{GF}}<1.25$ values at $D_{\mathrm{p}}=150 \mathrm{~nm}$. Although it is possible that part of these less hygroscopic particles were scavenged into cloud droplets, it is good to note that these cases were also characterized by notably low particle concentrations which may have led to increased uncertainties in activated fractions.

The difference between the activated and non-activated particles is also illustrated in Fig. 1 (lower panel) where the average GFs and GF-PDFs are presented separately for total, interstitial and residual aerosol populations. Here, the residual aerosol properties were estimated indirectly by using the hourly averaged total and interstitial GF-PDFs and the respective ambient particle concentrations as follows:

$$
\begin{aligned}
c_{\text {res }}\left(\mathrm{GF}, D_{\mathrm{p}}\right) & =\frac{d N_{\text {tot }}}{d \log D_{\mathrm{p}}}\left(D_{\mathrm{p}}\right) \times \mathrm{GF}-\mathrm{PDF}_{\text {tot }}\left(\mathrm{GF}, D_{\mathrm{p}}\right) \\
& -\frac{d N_{\text {int }}}{d \log D_{\mathrm{p}}}\left(D_{\mathrm{p}}\right) \times \mathrm{GF}-\mathrm{PDF}_{\text {int }}\left(\mathrm{GF}, D_{\mathrm{p}}\right) .
\end{aligned}
$$

Apparently, the relative contribution of less hygroscopic particles is the strongest in the interstitial population and the more hygroscopic mode appears distinctly only in the total and estimated residual aerosol. This is also reflected by the average growth factors. At $D_{\mathrm{p}}=120$ and $150 \mathrm{~nm}$, the GFs of cloud droplet residuals are approximately $18 \%$ higher than those of interstitial particles. In terms of $\kappa$ values, this discrepancy would correspond to a difference up to $65-75 \%$ depending on particle size. Again, it should be remarked that similar to activated fractions, the residual GF distributions $\left(c_{\text {res }}\right)$ can appear locally negative if the interstitial concentrations are higher than the respective total concentrations. Before converting these distributions into GF-PDFs shown in Fig. 1, the negative values were set to zeros which eventually strengthened the positive peaks appearing in normalized distributions. As a result, for example the less hygroscopic particle mode appearing in the estimated residual aerosol can be partially attributed to methodological uncertainties.

To our knowledge, this is one of the very few studies characterizing the hygroscopic properties of different in-cloud aerosol populations. Previously, Svenningsson et al. (1994) studied the aerosol hygroscopicity and its relationship to cloud droplet activation at Kleiner Feldberg in Germany. Interstitial aerosol hygroscopicity was measured during cloud events, and by assuming that the air mass was the same, it was compared to the total aerosol sampled during the following clear sky conditions. The less hygroscopic particle fraction was substantially higher in the interstitial population, indicating that the more hygroscopic particles were scavenged into the cloud droplets more efficiently than the less hygroscopic ones. This observation was confirmed in a case study, where a counter flow virtual impactor (CVI) was used to separate the cloud droplets from total aerosol, so that the hygroscopicity of cloud droplet residuals could be measured independently. Likewise, Rose et al. (2013) observed a decreasing fraction of available $\mathrm{CCN}$ during a precipitative cloud event, suggesting that the more hygroscopic particles were mostly activated into cloud droplets and removed from the air through precipitation. Overall, our results from Puijo are in good agreement with the observations reported by Svenningsson et al. (1994) and Rose et al. (2013).

In situ aerosol chemical composition and partitioning between activated and non-activated particles has been studied recently by means of aerosol mass spectrometry (e.g., Hao et al., 2013; Zelenyuk at al., 2010; Kamphus et al., 2010; 
Drewnick et al., 2007) and electron microscopy (Li et al., 2011). Based on the results from Puijo Cloud Experiment 2010, Hao et al. (2013) reported substantially higher mass fractions of organic nitrate and less oxidized organic species in the interstitial particles compared to residual ones. Similarly, Zelenyuk et al. (2010) and $\mathrm{Li}$ et al. (2011) observed an elevated fraction of sulfates in the activated particles. Although these results are broadly in line with our observations on the distinct hygroscopicity of activated and non-activated particles, great care should be taken when comparing the results. For example, Hao et al. (2013) observed an increased organic fraction in the Aitken mode particles, indicating that the differences in chemical composition also reflected the effect of particle size.

At Puijo, the critical droplet activation diameter, i.e., the diameter corresponding to the $50 \%$ activation efficiency (D50), varies typically between 100 and $200 \mathrm{~nm}$. According to our observations, this value is highly dependent on the prevailing hygroscopicity. To illustrate this relationship, the DMPS derived D50s (obtained from $f_{\text {act,DMPS }}$ via linear interpolation) were correlated with hourly averaged $\kappa$ values. Furthermore, a non-linear regression model D50 $\mathrm{a} \times \kappa^{-1 / 3}$ was chosen to account for the theoretical dependence addressed in Eq. (5). Figure 3 summarizes the results from all the observed cloud hours. Since the average hygroscopicity reflects the relative contribution of the two GF modes, the low-end $\kappa$ values were characterized by elevated $f_{\mathrm{GF}}<1.25$ and vice versa. Differing more than 3 standard deviations from the campaign average of $132 \mathrm{~nm}$, the data point with $\mathrm{D} 50=231 \mathrm{~nm}$ was excluded from the analysis as an outlier. Apart from this exception, the hourly D50s ranged from 93 to $173 \mathrm{~nm}$.

The $80 \mathrm{~nm}$ particles yielded the weakest correlation with root-mean-square error (RMSE) of $\sim 29 \mathrm{~nm}$. This could be expected since the $80 \mathrm{~nm}$ size usually remained well below the critical activation limit. On the contrary, the 120 and $150 \mathrm{~nm}$ sizes yielded the RMSE values around $\sim 13 \mathrm{~nm}$, suggesting a considerably stronger correlation between the two parameters. According to the linear correlations reported by Quinn et al. (2008), the chemical composition (parametrized as HOA mass fraction) explained approximately $40-50 \%$ of the variation in critical activation diameter. In comparison, applying a linear regression to our data set would result in $R^{2}$ values of $0.58(120 \mathrm{~nm})$ and $0.57(150 \mathrm{~nm})$. Assuming that the relationship between $\kappa$ and D50 could be treated as (locally) linear, these values would indicate that the accumulation mode hygroscopicity explained up to $57-58 \%$ of the observed variance in D50, therefore dominating the effect of varying meteorology and especially, the varying supersaturation. Moreover, no correlation was found between the $\kappa$ values and the estimated effective peak supersaturations $\left(R^{2} \sim 0.02\right.$; not shown here).
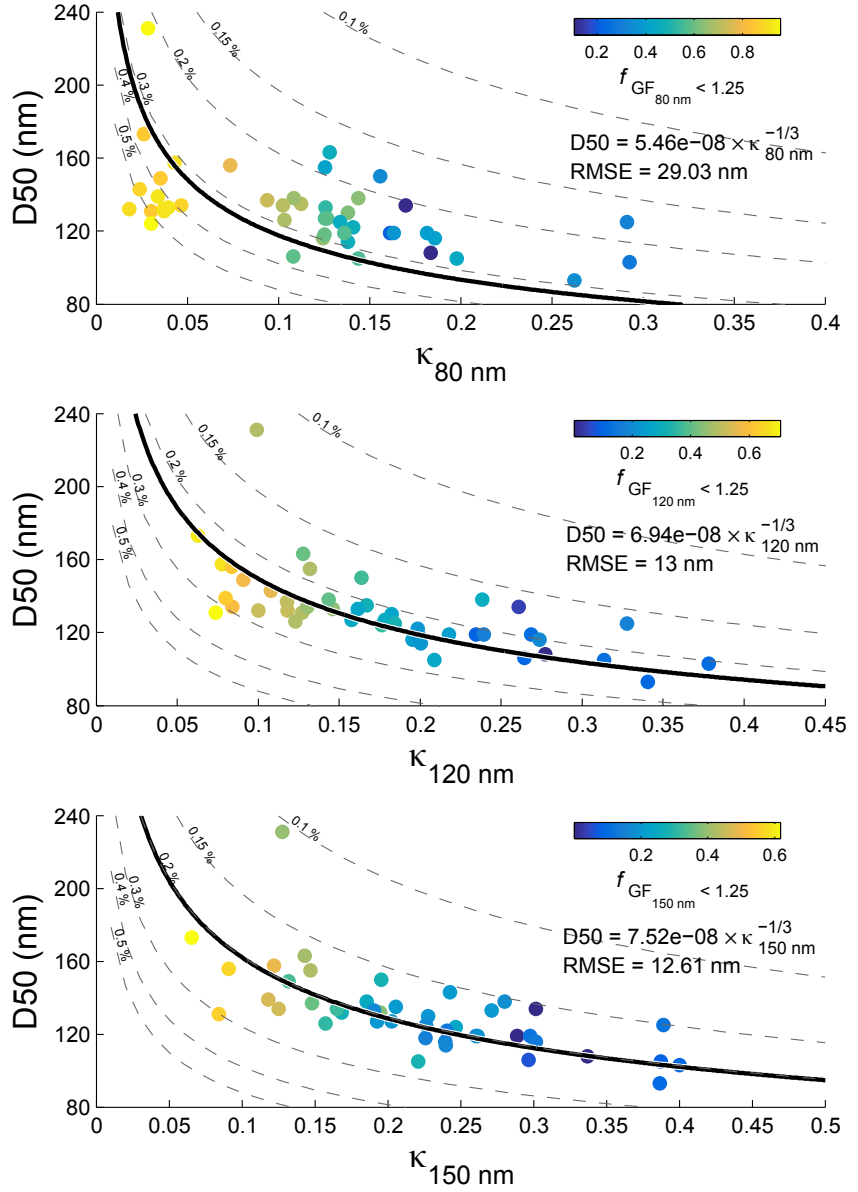

Figure 3. Critical activation diameter (D50) vs. size-averaged hygroscopicity $(\kappa)$ of 80,120 and $150 \mathrm{~nm}$ particles, as well as the power law fits (black lines) to the data. The data points are colored according to number fraction of less hygroscopic particles, and the grey dashed lines represent the numerical solutions of $\kappa$-Köhler theory in the range of $s_{\mathrm{C}}=0.1-0.5 \%$.

\section{4 $N_{\text {act,HTDMA }}$ and $s_{\mathrm{c}, \text { eff }}$}

The activation efficiency curves and the corresponding cloud droplet number concentrations were derived from the hourly averaged GF-PDFs according to the procedure described in Sect. 2.5. Reproducibility of the DMPS derived activation curves and cloud droplet nuclei spectra was confirmed visually, and the data points with considerable differences were omitted from the following analyses. In most of these cases, the estimated activation curves appeared clearly steeper than the measured ones, leading to both an underestimation of activated fraction at $D_{\mathrm{p}}<\mathrm{D} 50$ and an overestimation of activated fraction at $D_{\mathrm{p}}>\mathrm{D} 50$. Alternatively, some of the estimated curves managed to reproduce the correct behavior at smaller sizes $\left(D_{\mathrm{p}}<150 \mathrm{~nm}\right)$ but overestimated the activation at the size range of extrapolated GF-PDFs. Although these uncertainties caused only a small net bias to droplet estima- 


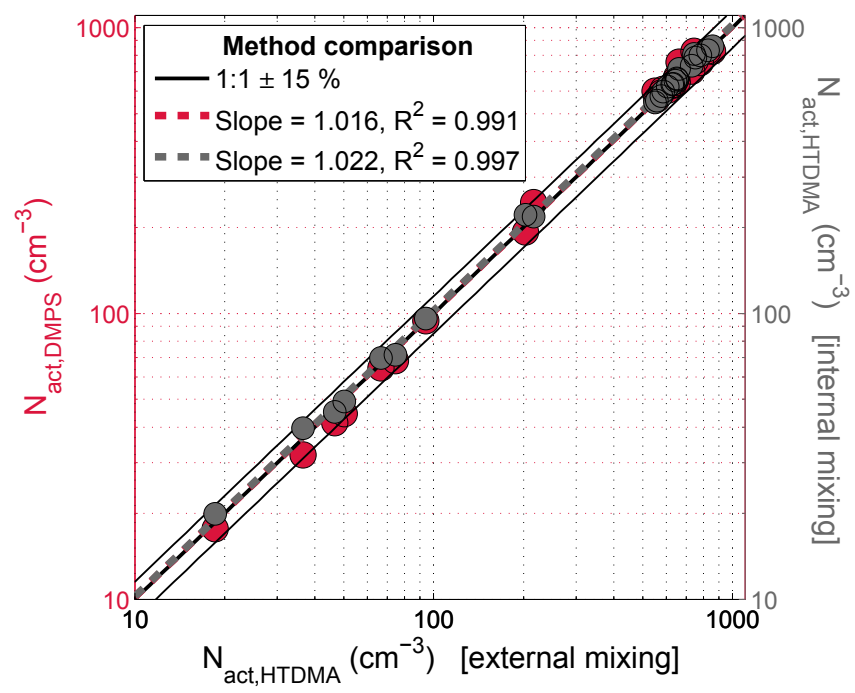

Figure 4. Correlations between the estimated (HTDMA) and measured (DMPS) cloud droplet concentrations (red dots) and the external and internal mixing approaches (grey dots). Each data point represents an hourly average.

tions, they indicate that the estimated GF surfaces may have failed to replicate the real ambient conditions.

Figure 4 shows a comparison between the HTDMA and DMPS derived cloud droplet concentrations (red dots). The regression line fitted through the 26 data points has a slope of 1.016 indicating a good agreement between the estimated and measured cloud droplet concentrations. In addition, Fig. 4 includes a comparison between the external and the internal mixing approaches (grey dots). Correspondingly, the regression line has a slope of 1.022 and all the hourly data points lie between the ratios 0.91 and 1.04. Analogous to Kammermann et al. (2010b), this observation suggests that the $\mathrm{CCN}$ concentration can be determined with reasonable accuracy even if the exact mixing state remains unknown. Nevertheless, since the determination of $N_{\text {act,HTDMA }}$ included the estimation of effective peak supersaturation by means of $f_{\text {act,DMPS }}$, the comparison shown here cannot be considered as a real CCN closure study in an explicit manner. Instead, it rather serves as a base for the analysis presented in the following section (Sect. 3.5).

Overall, the hourly estimated peak supersaturations ranged from $0.16 \%$ to $0.29 \%$. Apart from one exception with $s_{\mathrm{c} \text {,eff }}$ up to $0.44 \%$, this range was valid also for the omitted cloud hours. Although these values might be slightly biased due to the possible discrepancies between sub- and supersaturated hygroscopicities, they provide valuable information about the conditions relevant to cloud droplet formation. Reaching the average and median values of $0.22 \%$, the estimated $s_{\mathrm{c} \text {,eff }}$ values are comparable to supersaturations of $0.18-0.26 \%$ obtained by Anttila et al. (2009) at the Pallas GAW station in Northern Finland. Similar "average" supersaturations can be obtained also by using the regression curves presented in
Fig. 3. By assuming a constant temperature of $2{ }^{\circ} \mathrm{C}$ (average temperature of all the cloud hours), the regression parameters $6.94 \times 10^{-8}(120 \mathrm{~nm})$ and $7.52 \times 10^{-8}(150 \mathrm{~nm})$ imply supersaturations of 0.23 and $0.20 \%$, respectively. By contrast, these values are somewhat low compared to the highend supersaturations determined at some European mountain sites. For example, Asmi et al. (2012) found supersaturations ranging from $0.1 \%$ up to $0.6 \%$ at Puy-de-Dôme, and similarly, Hammer et al. (2014) observed a median peak supersaturation of $0.35 \%$ at Jungfraujoch. On the other hand, Hammer et al. (2014) also found a clear difference between the two dominant wind sectors reflecting the effect of terrain topography on updraft velocities. Generally, the air masses rising over the less steep mountainside were characterized by weaker updrafts and consequently, by supersaturations more comparable to ours (median $0.22 \%$ ).

\subsection{Sensitivity of cloud droplet formation to varying hygroscopicity}

Following the procedure described in Sect. 2.5, we performed $\kappa$-Köhler simulations to investigate how the cloud droplet concentrations would change if all the particles belonged to the more hygroscopic group. For each cloud hour, we created an alternative hygroscopicity scenario by modifying the original GF-PDFs. This alteration was conducted by eliminating the contribution of less hygroscopic particles and normalizing the resulting distributions so that the integral over each particle size became equal to one. In principle, the most significant changes appeared at sizes where the original $f_{\mathrm{GF}}<1.25$ were large enough to be affected by the modifications. Thus, instead of varying the GFs equally and regardless of particle size, the modifications only affected the presence of an existing low-GF mode and increased the average GFs accordingly.

Overview of the applied hygroscopic variations is presented in Table 2. Shown are average GFs at $D_{\mathrm{p}}=80,120$, 150 and $200 \mathrm{~nm}$ for the two hygroscopicity scenarios, as well as their absolute deviation from each other. In terms of $\kappa$ values, the high hygroscopicity assumption results in values between 0.20 and 0.40 . According to Andreae and Rosenfeld (2008), these values would be characteristic of typical aged continental aerosol. In order to highlight their atmospheric relevance, it is also important to note that they are within the range of hygroscopicities observed at Puijo during the campaign period. The cloud droplet concentrations were calculated for both scenarios by using identical particle size distributions as well as equal effective peak supersaturations.

Figure 5 shows the relative and absolute changes in $N_{\text {act,HTDMA }}$ against the hygroscopicity shift at $D_{\mathrm{p}}=150 \mathrm{~nm}$. Again, the data points are colored according to the less hygroscopic fraction, and the marker size is scaled relative to total particle number concentration. Naturally, the relative change in cloud droplet concentration increases with increasing hygroscopicity. Although most of the data points reside 
Table 2. Average GFs for reference and high hygroscopicity scenarios and their absolute deviation from each other. The values shown in the parentheses correspond to the minimum and maximum values. The GFs for $D_{\mathrm{p}}=80,120$ and $150 \mathrm{~nm}$ originate from direct measurements, whereas the data for $D_{\mathbf{p}}=200 \mathrm{~nm}$ is obtained via extrapolation.

\begin{tabular}{lllll}
\hline & $80 \mathrm{~nm}$ & $120 \mathrm{~nm}$ & $150 \mathrm{~nm}$ & $200 \mathrm{~nm}$ \\
\hline $\mathrm{GF}_{\text {avg }}$ [Reference] & $1.20(1.04 / 1.29)$ & $1.30(1.18 / 1.43)$ & $1.38(1.25 / 1.49)$ & $1.44(1.27 / 1.58)$ \\
$\mathrm{GF}_{\text {avg }}$ [High-GF] & $1.40(1.33 / 1.59)$ & $1.43(1.36 / 1.57)$ & $1.47(1.39 / 1.59)$ & $1.49(1.4 / 1.61)$ \\
$\Delta \mathrm{GF}_{\text {avg }}$ & $0.20(0.07 / 0.43)$ & $0.13(0.06 / 0.24)$ & $0.09(0.04 / 0.21)$ & $0.05(0 / 0.15)$ \\
\hline
\end{tabular}
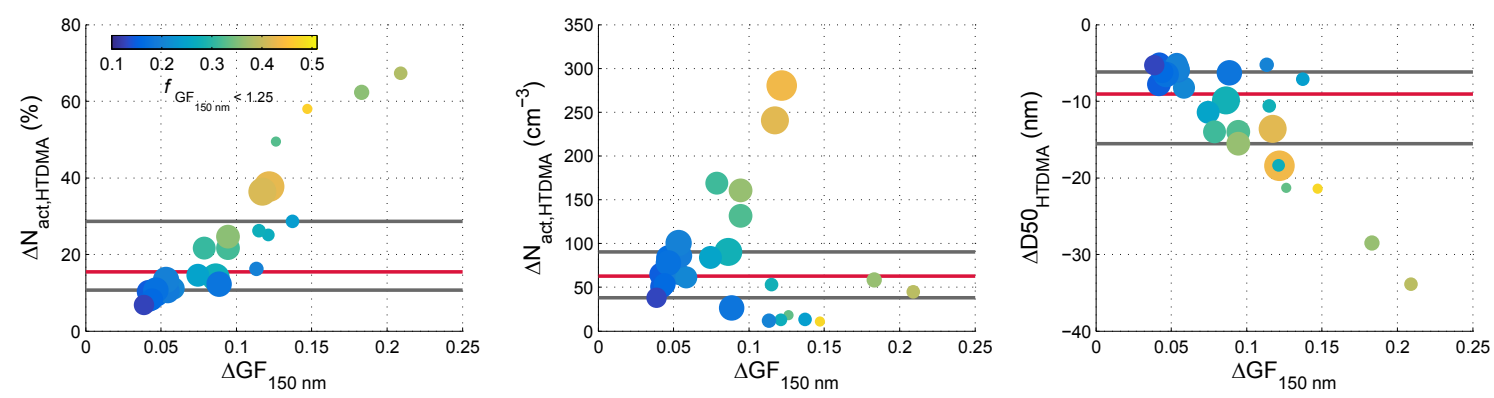

Figure 5. Simulated changes in cloud droplet number concentration $\left(N_{\text {act,HTDMA }}\right)$ and critical activation diameter (D50 HTDMA $)$ if all the particles belonged to the more hygroscopic mode. The marker size illustrates the total particle concentration in the range of $388 \mathrm{~cm}^{-3}$ to $3316 \mathrm{~cm}^{-3}$ and the data points are colored according to the less hygroscopic fraction (i.e., the fraction of particles merged into the more hygroscopic mode). The horizontal lines correspond to the 25th, 50th and 75th percentiles.

in the range of $10-40 \%$, the total variation extends up to $70 \%$. Furthermore, because of the approximately linear behavior of relative $\Delta N_{\text {act,HTDMA }}$, the absolute change appears highly sensitive to initial particle size distribution. In the case of high total concentration, the absolute $\Delta N_{\text {act,HTDMA }}$ can be up to hundreds of droplets per cubic centimeter even with reasonably small hygroscopic variations $\left(\Delta \mathrm{GF}_{150 \mathrm{~nm}}<0.10\right)$.

In addition to droplet concentration, Fig. 5 illustrates the change in critical activation diameter (D50 HTDMA; derived from $f_{\text {act,HTDMA }}$ via linear interpolation). Understandably, as the high hygroscopicity assumption suppresses the sizedependence of aerosol hygroscopicity (see Table 2), the activation efficiency curves become steeper and D50s decrease. Typically, the change in D50 remains below $20 \mathrm{~nm}$ but can reach $35 \mathrm{~nm}$ in the most extreme cases.

Anttila et al. (2009) studied the effect of varying hygroscopicity at the Pallas GAW station in Northern Finland. According to the simulations, increasing the GFs by $10 \%$ led to $17-51 \%$ increments in cloud droplet number concentration. Bearing in mind that a $10 \%$ relative change in GFs corresponded to an absolute change of $\sim 0.13$ at $D_{\mathrm{p}}=150 \mathrm{~nm}$, the observations by Anttila et al. (2009) are in good agreement with our results. However, it is also worth pointing out that by increasing all the GFs by $10 \%$, the absolute change in growth factors increased with particle size. In our analysis, removal of the less hygroscopic mode induced the opposite effect.

Similar to our analysis, Wex et al. (2010) assessed the overestimation of $\mathrm{CCN}$ concentration if all the particles were assumed to have $\kappa$ of the more hygroscopic particles. By using data from the literature, the overestimation was derived for rural, urban and marine aerosol populations and for different less hygroscopic fractions. In the case of urban and rural aerosols, the overestimation varied between $20-40$ and $40-100 \%$ when the less hygroscopic fraction $(\kappa<0.10)$ was set to 0.3 and 0.5 . With the range of variation illustrating the inverse proportionality to supersaturation (between 0.1 and $0.5 \%$ ), these values are comparable to our observations. However, Wex et al. (2010) assumed the same less hygroscopic fraction for all particle sizes, which is very rarely the case in our conditions at Puijo.

Kammermann et al. (2010b) performed a set of CCN closure studies to investigate the sensitivity of $\mathrm{CCN}$ concentration to unknown chemical composition. The median bias between the predicted and measured $\mathrm{CCN}$ concentrations was up to $+54 \%$ when a constant $\kappa=0.30$ was assumed. Analogous to our observations, the average hygroscopicities reported by Kammermann et al. (2010b) were relatively low explaining the remarkable bias in $\mathrm{CCN}$ predictions. On the contrary, Meng et al. (2014) found a reasonably good agreement between the measured and predicted $\mathrm{CCN}$ concentrations by using a constant $\kappa$ as high as 0.33 at a coastal site in Hong Kong, where the aerosol composition was dominated by inorganic species.

In principle, the high hygroscopicity assumption yields values resembling the hygroscopicities that could be obtained from bulk composition measurements by means of aerosol mass spectrometry. Typically, the bulk composition 
is biased towards the inorganics due to the emphasis on larger particles. This can lead to a considerable overestimation of CCN concentration. For example, Medina et al. (2007), Almeida et al. (2014) and Meng et al. (2014) reported an overprediction of $26-44 \%$ at $\sim 0.20 \%$ supersaturation when only the size-averaged composition was considered. In all of these studies, implementing the size-dependent or sizeresolved chemical composition substantially improved the $\mathrm{CCN}$ predictions.

\section{Summary and conclusions}

The relationship between aerosol hygroscopicity and cloud droplet activation was studied at the Puijo measurement station in Kuopio, Finland during the Puijo Cloud Experiment 2014. The purpose of the campaign was to identify the hygroscopicity-dependent activation properties of a cloud forming aerosol population, as well as to study the sensitivity of cloud droplet activation to varying chemical composition in real atmospheric in-cloud conditions. In total, 15 nonprecipitating cloud events were observed during the 2-month long campaign providing a total of 47 cloud hours.

The aerosol hygroscopicity at $90 \% \mathrm{RH}$ was measured with an HTDMA. Typically, the measured GF-PDFs appeared bimodal, indicating an externally mixed aerosol population. By using the GF-PDFs and particle concentrations measured separately for interstitial and total aerosol populations, the hygroscopicity-dependent activation properties were estimated. The growth factor distributions were divided into low and high hygroscopicity regimes by using a GF limit of 1.25 and the activated fraction in each category was calculated.

The in-cloud measurements revealed clear differences in activation efficiency between the two GF modes. The less hygroscopic particles originating most likely from local anthropogenic sources remained mostly non-activated, whereas the more hygroscopic mode was primarily scavenged into cloud droplets. This observation highlights the role of aerosol hygroscopicity and chemical composition in cloud droplet activation. A highly variable portion of less hygroscopic particles has been observed in several studies and in many different locations during the last few decades. Due to the anthropogenic contribution, the less hygroscopic mode can be dominant at particle sizes up to $250 \mathrm{~nm}$. As shown by our analysis, this can lead to a significant decrease in the fraction of available $\mathrm{CCN}$.

By modifying the measured GF-PDFs, we estimated how the cloud droplet concentrations would change if all the particles belonged to the more hygroscopic mode. This would correspond to a situation with typical aged, continental aerosol in the atmosphere without any fresh anthropogenic influence. According to the $\kappa$-Köhler simulations, the change in cloud droplet concentration was up to $70 \%$ when the possible feedback effects on cloud supersaturation were assumed negligible. Our result clearly demonstrates the importance of correct treatment of anthropogenic organic aerosols, their hygroscopicity and the effect of atmospheric aging, when estimating $\mathrm{CCN}$ concentrations.

\section{Data availability}

All the measurement data are available upon request from the corresponding author (annele.virtanen@uef.fi).

\section{The Supplement related to this article is available online at doi:10.5194/acp-16-10385-2016-supplement.}

Acknowledgements. This work was supported by the European Research Council (ERC starting grant 335478), the Academy of Finland (grant nos. 272041, 259005, 283031) and The Doctoral School of the University of Eastern Finland. In addition, Antti Ruuskanen acknowledges the financial support from Maj and Tor Nessling Foundation.

Edited by: H. Su

Reviewed by: M. Gysel and two anonymous referees

\section{References}

Ahmad, I., Mielonen, T., Grosvenor, D. P., Portin, H. J., Arola, A., Mikkonen, S., Kuhn, T., Leskinen, A., Joutsensaari, J., Komppula, M., Lehtinen, K. E. J., Laaksonen, A., and Romakkaniemi, S.: Long-term measurements of cloud droplet concentrations and aerosol-cloud interactions in continental boundary layer clouds, Tellus B, 65, 20138, doi:10.3402/Tellusb.V65i0.20138, 2013.

Almeida, G. P., Brito, J., Morales, C. A., Andrade, M. F., and Artaxo, P.: Measured and modelled cloud condensation nuclei $(\mathrm{CCN})$ concentration in Sao Paulo, Brazil: the importance of aerosol size-resolved chemical composition on CCN concentration prediction, Atmos. Chem. Phys., 14, 7559-7572, doi:10.5194/acp-14-7559-2014, 2014.

Andreae, M. O. and Rosenfeld, D.: Aerosol-cloudprecipitation interactions. Part 1 . The nature and sources of cloud-active aerosols, Earth.-Sci. Rev., 89, 13-41, doi:10.1016/j.earscirev.2008.03.001, 2008.

Anttila, T., Vaattovaara, P., Komppula, M., Hyvärinen, A.-P., Lihavainen, H., Kerminen, V.-M., and Laaksonen, A.: Sizedependent activation of aerosols into cloud droplets at a subarctic background site during the second Pallas Cloud Experiment (2nd PaCE): method development and data evaluation, Atmos. Chem. Phys., 9, 4841-4854, doi:10.5194/acp-9-4841-2009, 2009.

Asmi, E., Freney, E., Hervo, M., Picard, D., Rose, C., Colomb, A., and Sellegri, K.: Aerosol cloud activation in summer and winter at puy-de-Dome high altitude site in France, Atmos. Chem. Phys., 12, 11589-11607, doi:10.5194/acp-12-11589-2012, 2012.

Broekhuizen, K., Chang, R. Y.-W., Leaitch, W. R., Li, S.-M., and Abbatt, J. P. D.: Closure between measured and modeled cloud 
condensation nuclei $(\mathrm{CCN})$ using size-resolved aerosol compositions in downtown Toronto, Atmos. Chem. Phys., 6, 2513-2524, doi:10.5194/acp-6-2513-2006, 2006.

Conant, W. C., VanReken, T. M., Rissman, T. A., Varutbangkul, V., Jonsson, H. H., Nenes, A., Jimenez, J. L., Delia, A. E., Bahreini, R., Roberts, G. C., Flagan, R. C., and Seinfeld, J. H.: Aerosolcloud drop concentration closure in warm cumulus, J. Geophys. Res.-Atmos., 109, D13204, doi:10.1029/2003jd004324, 2004.

Drewnick, F., Schneider, J., Hings, S. S., Hock, N., Noone, K., Targino, A., Weimer, S., and Borrmann, S.: Measurement of ambient, interstitial, and residual aerosol particles on a mountaintop site in central Sweden using an aerosol mass spectrometer and a CVI, J. Atmos. Chem., 56, 1-20, doi:10.1007/s10874-006-90368, 2007.

Dusek, U., Frank, G. P., Hildebrandt, L., Curtius, J., Schneider, J., Walter, S., Chand, D., Drewnick, F., Hings, S., Jung, D., Borrmann, S., and Andreae, M. O.: Size matters more than chemistry for cloud-nucleating ability of aerosol particles, Science, 312, 1375-1378, doi:10.1126/science.1125261, 2006.

Ervens, B., Cubison, M., Andrews, E., Feingold, G., Ogren, J. A., Jimenez, J. L., DeCarlo, P., and Nenes, A.: Prediction of cloud condensation nucleus number concentration using measurements of aerosol size distributions and composition and light scattering enhancement due to humidity, J. Geophys. Res.-Atmos., 112, D10S32, doi:10.1029/2006JD007426, 2007.

Ferron, G. A., Karg, E., Busch, B., and Heyder, J.: Ambient particles at an urban, semi-urban and rural site in Central Europe: hygroscopic properties, Atmos. Environ., 39, 343-352, doi:10.1016/j.atmosenv.2004.09.015, 2005.

Fitzgerald, J.: Dependence of the Supersaturation Spectrum of $\mathrm{CCN}$ on Aerosol Size Distribution and Composition, J. Atmos. Sci., 30, 628-634, doi:10.1175/15200469(1973)030<0628:DOTSSO>2.0.CO;2, 1973.

Fors, E. O., Swietlicki, E., Svenningsson, B., Kristensson, A., Frank, G. P., and Sporre, M.: Hygroscopic properties of the ambient aerosol in southern Sweden - a two year study, Atmos. Chem. Phys., 11, 8343-8361, doi:10.5194/acp-11-8343-2011, 2011.

Fountoukis, C., Nenes, A., Meskhidze, N., Bahreini, R., Conant, W. C., Jonsson, H., Murphy, S., Sorooshian, A., Varutbangkul, V., Brechtel, F., Flagan, R. C., and Seinfeld, J. H.: Aerosol-cloud drop concentration closure for clouds sampled during the International Consortium for Atmospheric Research on Transport and Transformation 2004 campaign, J. Geophys. Res.-Atmos., 112, D10S30, doi:10.1029/2006jd007272, 2007.

Good, N., Topping, D. O., Allan, J. D., Flynn, M., Fuentes, E., Irwin, M., Williams, P. I., Coe, H., and McFiggans, G.: Consistency between parameterisations of aerosol hygroscopicity and CCN activity during the RHaMBLe discovery cruise, Atmos. Chem. Phys., 10, 3189-3203, doi:10.5194/acp-10-3189-2010, 2010.

Gysel, M., McFiggans, G. B., and Coe, H.: Inversion of tandem differential mobility analyser (TDMA) measurements, J Aerosol Sci., 40, 134-151, doi:10.1016/j.jaerosci.2008.07.013, 2009.

Hammer, E., Bukowiecki, N., Gysel, M., Juranyi, Z., Hoyle, C. R., Vogt, R., Baltensperger, U., and Weingartner, E.: Investigation of the effective peak supersaturation for liquid-phase clouds at the high-alpine site Jungfraujoch, Switzerland (3580 m a.s.1.), Atmos. Chem. Phys., 14, 1123-1139, doi:10.5194/acp-14-11232014, 2014.
Hao, L. Q., Romakkaniemi, S., Kortelainen, A., Jaatinen, A., Portin, H., Miettinen, P., Komppula, M., Leskinen, A., Virtanen, A., Smith, J. N., Sueper, D., Worsnop, D. R., Lehtinen, K. E. J., and Laaksonen, A.: Aerosol Chemical Composition in Cloud Events by High Resolution Time-of-Flight Aerosol Mass Spectrometry, Environ. Sci. Technol., 47, 2645-2653, doi:10.1021/es302889w, 2013.

Henning, S., Dieckmann, K., Ignatius, K., Schafer, M., Zedler, P., Harris, E., Sinha, B., van Pinxteren, D., Mertes, S., Birmili, W., Merkel, M., Wu, Z., Wiedensohler, A., Wex, H., Herrmann, H., and Stratmann, F.: Influence of cloud processing on CCN activation behaviour in the Thuringian Forest, Germany during HCCT2010, Atmos. Chem. Phys., 14, 7859-7868, doi:10.5194/acp-147859-2014, 2014.

Hersey, S. P., Craven, J. S., Metcalf, A. R., Lin, J., Lathem, T., Suski, K. J., Cahill, J. F., Duong, H. T., Sorooshian, A., Jonsson, H. H., Shiraiwa, M., Zuend, A., Nenes, A., Prather, K. A., Flagan, R. C., and Seinfeld, J. H.: Composition and hygroscopicity of the Los Angeles Aerosol: CalNex, J. Geophys. Res.-Atmos., 118, 30163036, doi:10.1002/jgrd.50307, 2013.

Hudson, J. G.: Variability of the relationship between particle size and cloud-nucleating ability, Geophys. Res. Lett., 34, L08801, doi:10.1029/2006gl028850, 2007.

IPCC: Climate change 2013: The physical science basis. Intergovernmental panel on Climate Change, Cambridge University Press, New York, 13-14, 2013.

Jaatinen, A., Romakkaniemi, S., Anttila, T., Hyvarinen, A. P., Hao, L. Q., Kortelainen, A., Miettinen, P., Mikkonen, S., Smith, J. N., Virtanen, A., and Laaksonen, A.: The third Pallas Cloud Experiment: Consistency between the aerosol hygroscopic growth and CCN activity, Boreal Environ. Res., 19, 368-382, 2014.

Junge, C. M. E.: Relationship of Cloud Nuclei Spectra to Aerosol Size Distribution and Composition, J. Atmos. Sci., 28, 282-390, 1971.

Jurányi, Z., Tritscher, T., Gysel, M., Laborde, M., Gomes, L., Roberts, G., Baltensperger, U., and Weingartner, E.: Hygroscopic mixing state of urban aerosol derived from sizeresolved cloud condensation nuclei measurements during the MEGAPOLI campaign in Paris, Atmos. Chem. Phys., 13, 64316446, doi:10.5194/acp-13-6431-2013, 2013.

Kammermann, L., Gysel, M., Weingartner, E., and Baltensperger, U.: 13-month climatology of the aerosol hygroscopicity at the free tropospheric site Jungfraujoch (3580 ma.s.1.), Atmos. Chem. Phys., 10, 10717-10732, doi:10.5194/acp-10-107172010, 2010a.

Kammermann, L., Gysel, M., Weingartner, E., Herich, H., Cziczo, D. J., Holst, T., Svenningsson, B., Arneth, A., and Baltensperger, U.: Subarctic atmospheric aerosol composition: 3. Measured and modeled properties of cloud condensation nuclei, J. Geophys. Res.-Atmos., 115, D04202, doi:10.1029/2009jd012447, 2010 b.

Kamphus, M., Ettner-Mahl, M., Klimach, T., Drewnick, F., Keller, L., Cziczo, D. J., Mertes, S., Borrmann, S., and Curtius, J.: Chemical composition of ambient aerosol, ice residues and cloud droplet residues in mixed-phase clouds: single particle analysis during the Cloud and Aerosol Characterization Experiment (CLACE 6), Atmos. Chem. Phys., 10, 8077-8095, doi:10.5194/acp-10-8077-2010, 2010.

Komppula, M., Lihavainen, H., Kerminen, V. M., Kulmala, M., and Viisanen, Y.: Measurements of cloud droplet activation of aerosol 
particles at a clean subarctic background site, J. Geophys. Res.Atmos., 110, D06204, doi:10.1029/2004jd005200, 2005.

Köhler, H.: The nucleus in and the growth of hygroscopic droplets, Trans. Faraday Soc., 32, 1152-1161, doi:10.1039/TF9363201152, 1936.

Laborde, M., Crippa, M., Tritscher, T., Juranyi, Z., Decarlo, P. F., Temime-Roussel, B., Marchand, N., Eckhardt, S., Stohl, A., Baltensperger, U., Prevot, A. S. H., Weingartner, E., and Gysel, M.: Black carbon physical properties and mixing state in the European megacity Paris, Atmos. Chem. Phys., 13, 5831-5856, doi:10.5194/acp-13-5831-2013, 2013.

Leskinen, A., Portin, H., Komppula, M., Miettinen, P., Arola, A., Lihavainen, H., Hatakka, J., Laaksonen, A., and Lehtinen, K. E. J.: Overview of the research activities and results at Puijo semiurban measurement station, Boreal Environ. Res., 14, 576-590, 2009.

Leskinen, A., Arola, A., Komppula, M., Portin, H., Tiitta, P., Miettinen, P., Romakkaniemi, S., Laaksonen, A., and Lehtinen, K. E. J.: Seasonal cycle and source analyses of aerosol optical properties in a semi-urban environment at Puijo station in Eastern Finland, Atmos. Chem. Phys., 12, 5647-5659, doi:10.5194/acp-12-56472012, 2012.

Li, W. J., Li, P. R., Sun, G. D., Zhou, S. Z., Yuan, Q., and Wang, W. X.: Cloud residues and interstitial aerosols from non-precipitating clouds over an industrial and urban area in northern China, Atmos. Environ., 45, 2488-2495, doi:10.1016/j.atmosenv.2011.02.044, 2011.

Liu, P. F., Zhao, C. S., Gobel, T., Hallbauer, E., Nowak, A., Ran, L., Xu, W. Y., Deng, Z. Z., Ma, N., Mildenberger, K., Henning, S., Stratmann, F., and Wiedensohler, A.: Hygroscopic properties of aerosol particles at high relative humidity and their diurnal variations in the North China Plain, Atmos. Chem. Phys., 11, 3479-3494, doi:10.5194/acp-11-3479-2011, 2011.

Liu, D., Allan, J., Whitehead, J., Young, D., Flynn, M., Coe, H., McFiggans, G., Fleming, Z. L., and Bandy, B.: Ambient black carbon particle hygroscopic properties controlled by mixing state and composition, Atmos. Chem. Phys., 13, 2015-2029, doi:10.5194/acp-13-2015-2013, 2013.

McFiggans, G., Artaxo, P., Baltensperger, U., Coe, H., Facchini, M. C., Feingold, G., Fuzzi, S., Gysel, M., Laaksonen, A., Lohmann, U., Mentel, T. F., Murphy, D. M., O’Dowd, C. D., Snider, J. R., and Weingartner, E.: The effect of physical and chemical aerosol properties on warm cloud droplet activation, Atmos. Chem. Phys., 6, 2593-2649, doi:10.5194/acp-6-2593-2006, 2006.

Medina, J., Nenes, A., Sotiropoulou, R. E. P., Cottrell, L. D., Ziemba, L. D., Beckman, P. J., and Griffin, R. J.: Cloud condensation nuclei closure during the International Consortium for Atmospheric Research on Transport and Transformation 2004 campaign: Effects of size-resolved composition, J. Geophys. Res.Atmos., 112, D10S31, doi:10.1029/2006jd007588, 2007.

Meng, J. W., Yeung, M. C., Li, Y. J., Lee, B. Y. L., and Chan, C. K.: Size-resolved cloud condensation nuclei (CCN) activity and closure analysis at the HKUST Supersite in Hong Kong, Atmos. Chem. Phys., 14, 10267-10282, doi:10.5194/acp-1410267-2014, 2014.

Pajunoja, A., Lambe, A. T., Hakala, J., Rastak, N., Cummings, M. J., Brogan, J. F., Hao, L. Q., Paramonov, M., Hong, J., Prisle, N. L., Malila, J., Romakkaniemi, S., Lehtinen, K. E. J., Laaksonen, A., Kulmala, M., Massoli, P., Onasch, T. B., Donahue,
N. M., Riipinen, I., Davidovits, P., Worsnop, D. R., Petaja, T., and Virtanen, A.: Adsorptive uptake of water by semisolid secondary organic aerosols, Geophys. Res. Lett., 42, 3063-3068, doi:10.1002/2015GL063142, 2015.

Petters, M. D. and Kreidenweis, S. M.: A single parameter representation of hygroscopic growth and cloud condensation nucleus activity, Atmos. Chem. Phys., 7, 1961-1971, doi:10.5194/acp-71961-2007, 2007.

Portin, H. J., Komppula, M., Leskinen, A. P., Romakkaniemi, S., Laaksonen, A., and Lehtinen, K. E. J.: Observations of aerosolcloud interactions at the Puijo semi-urban measurement station, Boreal Environ. Res., 14, 641-653, 2009.

Portin, H., Leskinen, A., Hao, L., Kortelainen, A., Miettinen, P., Jaatinen, A., Laaksonen, A., Lehtinen, K. E. J., Romakkaniemi, S., and Komppula, M.: The effect of local sources on particle size and chemical composition and their role in aerosol-cloud interactions at Puijo measurement station, Atmos. Chem. Phys., 14, 6021-6034, doi:10.5194/acp-14-6021-2014, 2014.

Quinn, P. K., Bates, T. S., Coffman, D. J., and Covert, D. S.: Influence of particle size and chemistry on the cloud nucleating properties of aerosols, Atmos. Chem. Phys., 8, 1029-1042, doi:10.5194/acp-8-1029-2008, 2008.

Rose, D., Gunthe, S. S., Jurányi, Z., Gysel, M., Frank, G. P., Schneider, J., Curtius, J., and Pöschl, U.: Size-resolved and integral measurements of cloud condensation nuclei $(\mathrm{CCN})$ at the high-alpine site Jungfraujoch, Atmos. Chem. Phys. Discuss., 13, 32575-32624, doi:10.5194/acpd-13-32575-2013, 2013.

Sjogren, S., Gysel, M., Weingartner, E., Alfarra, M. R., Duplissy, J., Cozic, J., Crosier, J., Coe, H., and Baltensperger, U.: Hygroscopicity of the submicrometer aerosol at the high-alpine site Jungfraujoch, $3580 \mathrm{~m}$ a.s.l., Switzerland, Atmos. Chem. Phys., 8, 5715-5729, doi:10.5194/acp-8-5715-2008, 2008.

Svenningsson, B., Hansson, H. C., Wiedensohler, A., Noone, K., Ogren, J., Hallberg, A., and Colvile, R.: Hygroscopic Growth of Aerosol-Particles and Its Influence on Nucleation Scavenging inCloud - Experimental Results from Kleiner-Feldberg, J. Atmos. Chem., 19, 129-152, doi:10.1007/Bf00696586, 1994.

Tiitta, P., Miettinen, P., Vaattovaara, P., Joutsensaari, J., Petaja, T., Virtanen, A., Raatikainen, T., Aalto, P., Portin, H., Romakkaniemi, S., Kokkola, H., Lehtinen, K. E. J., Kulmala, M., and Laaksonen, A.: Roadside aerosol study using hygroscopic, organic and volatility TDMAs: Characterization and mixing state, Atmos. Environ., 44, 976-986, doi:10.1016/j.atmosenv.2009.06.021, 2010.

Weingartner, E., Burtscher, H., and Baltensperger, U.: Hygroscopic properties of carbon and diesel soot particles, Atmos. Environ., 31, 2311-2327, doi:10.1016/S1352-2310(97)00023-X, 1997.

Wex, H., McFiggans, G., Henning, S., and Stratmann, F.: Influence of the external mixing state of atmospheric aerosol on derived CCN number concentrations, Geophys. Res. Lett., 37, L10805, doi:10.1029/2010g1043337, 2010.

Wiedensohler, A., Birmili, W., Nowak, A., Sonntag, A., Weinhold, K., Merkel, M., Wehner, B., Tuch, T., Pfeifer, S., Fiebig, M., Fjaraa, A. M., Asmi, E., Sellegri, K., Depuy, R., Venzac, H., Villani, P., Laj, P., Aalto, P., Ogren, J. A., Swietlicki, E., Williams, P., Roldin, P., Quincey, P., Huglin, C., Fierz-Schmidhauser, R., Gysel, M., Weingartner, E., Riccobono, F., Santos, S., Gruning, C., Faloon, K., Beddows, D., Harrison, R. M., Monahan, C., Jennings, S. G., O’Dowd, C. D., Marinoni, A., Horn, H. G., Keck, 
L., Jiang, J., Scheckman, J., McMurry, P. H., Deng, Z., Zhao, C. S., Moerman, M., Henzing, B., de Leeuw, G., Loschau, G., and Bastian, S.: Mobility particle size spectrometers: harmonization of technical standards and data structure to facilitate high quality long-term observations of atmospheric particle number size distributions, Atmos. Meas. Tech., 5, 657-685, doi:10.5194/amt5-657-2012, 2012.

Winklmayr, W., Reischl, G. P., Lindner, A. O., and Berner, A.: A New Electromobility Spectrometer for the Measurement of Aerosol Size Distributions in the Size Range from 1 to 1000 Nm, J. Aerosol Sci., 22, 289-296, doi:10.1016/S00218502(05)80007-2, 1991.
Vlasenko, A., Sjogren, S., Weingartner, E., Gaggeler, H. W., and Ammann, M.: Generation of submicron Arizona test dust aerosol: Chemical and hygroscopic properties, Aerosol. Sci. Tech., 39, 452-460, doi:10.1080/027868290959870, 2005.

Zelenyuk, A., Imre, D., Earle, M., Easter, R., Korolev, A., Leaitch, R., Liu, P., Macdonald, A. M., Ovchinnikov, M., and Strapp, W.: In Situ Characterization of Cloud Condensation Nuclei, Interstitial, and Background Particles Using the Single Particle Mass Spectrometer, SPLAT II, Anal. Chem., 82, 7943-7951, doi:10.1021/ac1013892, 2010. 